\title{
Studies on Compatibility of Poly(ethylene oxide) and Poly(methyl methacrylate) by Inverse Gas Chromatography
}

\author{
Yoshimasa MURAKAMI \\ Faculty of Liberal Arts, Shinshu University, \\ 3-1-1 Asahi, Matsumoto, Nagano 390, Japan
}

(Received November 2, 1987)

\begin{abstract}
Transition phenomena in polymer blends of poly(ethylene oxide) (PEO) and poly(methyl methacrylate) (PMMA) of various compositions were investigated by inverse gas chromatography. Below $c a .15 \mathrm{wt} \%$ PEO, the polymer system was almost homogeneous and the transition behavior of the blends was mainly dominated by PMMA. In $c a$. $25-45 \mathrm{wt} \%$ PEO, the two components were completely compatible and the transition behavior of the blends was mainly governed by PEO. In $c a .15-25 \mathrm{wt} \%$ PEO, the transition behavior was greatly changed by thermal treatment. This composition range corresponded to a critical state of the above-mentioned two states. Above $\mathrm{ca} .45 \mathrm{wt} \%$ PEO, PEO domains were segregated in the homogeneous polymer matrix and spread out with increase in PEO content. In the linear triblock copolymers of PEO and PMMA, compatibility was essentially identical to that in the blend, while it greatly depended on the molecular structure in the PEO-grafted block copolymers of PEO and PMMA.

KEY WORDS Inverse Gas Chromatography / Transition Behavior / Poly(ethylene oxide) / Poly(methyl methacrylate) / Polymer Blend / Block Copolymer / Phase Separation / Compatibility / Scanning Electron Microscopy / Thermal Treatment /
\end{abstract}

In recent years compatibility of multicomponent polymer systems such as polymer blends and block copolymers has been extensively investigated by various methods. ${ }^{1-6}$ Inverse gas chromatography (IGC), which has been developed by Guillet and co-workers, ${ }^{7}$ has been used to characterize copolymers. ${ }^{8-12} \mathrm{By}$ using IGC, we investigated the morphology of hydrophilic-hydrophobic polymer systems such as polymer blends of poly(ethylene oxide) (PEO) and polystyrene (PS), ${ }^{13,14}$ poly(acrylic acid) and PS, ${ }^{15}$ and block copolymers of PEO and poly(methyl methacrylate) (PMMA). ${ }^{16}$

In the previous study, we discussed the transition phenomena in various block copolymers of PEO and PMMA(PEO- $b$-PMMA) and an intramolecular plasticizing effect was elucidated. ${ }^{16}$ The morphological study of
PEO/PMMA blends is of great interest, since they consist of hydrophilic and hydrophobic polymers and are expected to be compatible. Several studies on PEO/PMMA blends have been reported. ${ }^{17-20}$ Depressions of both melting temperature $\left(T_{\mathrm{m}}\right)$ of PEO and glass transition temperature $\left(T_{\mathrm{g}}\right)$ of PMMA were observed. ${ }^{17,18}$ Further, the interaction parameter ${ }^{19}$ and thermal degradation ${ }^{20}$ of the blend were investigated. However, the change in the compatibility of the components with the composition has not yet been reported.

In this study, we investigated the transition phenomena of PEO/PMMA blends of various compositions by IGC. In the present paper, we report the influence of composition on the compatibility of the two components and the results are compared with those of PEO- $b$ - 
PMMA reported previously. ${ }^{16}$ The effect of thermal treatment on the compatibility is also discussed.

\section{EXPERIMENTAL}

\section{Materials}

Nakarai Chemical's PEO \#6000 $\left(\bar{M}_{n}=8500\right)$ was used as received. PMMA $\left(\bar{M}_{n}=46800\right)$ was prepared by radical polymerization of methyl methacrylate (MMA) in benzene at $60^{\circ} \mathrm{C}$ initiated with AIBN. Linear triblock copolymers of PEO and PMMA (PMMAPEO-PMMA, li-block) and PEO-grafted block copolymers of PEO and PMMA (grblock) were also investigated. Since a transesterification reaction between the disodium salt of PEO and the methoxy group in MMA occurred during the polymerization, PEO blocks grafted on PMMA blocks in gr-block. PEO content in these copolymers was determined by NMR analysis. The details of the preparation and characterization of these block copolymers have been described in previous papers. $^{21-23}$ Benzene and Chromosorb P AW-DMCS 60/80 mesh were used as solvent and support, respectively. ${ }^{24}$ Trimethylchlorosilane and hexamethyldisilazane were used for silane-treatment of the glass plate surface on which a polymer film was cast.

\section{Measurements}

The columns used in this study are described in Table I. Their preparation has been described in detail in previous papers. ${ }^{13-16}$

Gas chromatograms were recorded on a Shimadzu GC-8A equipped with a thermal conductivity detector, with helium as a carrier gas, $n$-nonane as a solute, and air as a noninteracting marker. The method of IGC measurement has been described in previous papers. ${ }^{13-16}$ The measurement was carried out by increasing the column temperature $T(\mathrm{~K})$. The retention diagram (RD) was obtained by plotting $\log V_{\mathrm{g}}$ versus $10^{3} / T$ ( $V_{\mathrm{g}}$ is the specific retention volume of the solute: $\mathrm{mlg}^{-1}$ ).
Table I. Column specifications

\begin{tabular}{|c|c|c|c|}
\hline \multirow{2}{*}{$\begin{array}{c}\text { Column } \\
\text { No. }\end{array}$} & \multirow{2}{*}{ Polymer } & \multirow{2}{*}{$\frac{\text { PEO content }}{w t \%}$} & \multirow{2}{*}{$\frac{\text { Polymer loading }^{\mathrm{a}}}{w \mathrm{wt}^{\circ} \%}$} \\
\hline & & & \\
\hline 1 & PMMA & 0 & 9.7 \\
\hline 2 & Blend & 5 & 9.7 \\
\hline 3 & Blend & 10 & 9.7 \\
\hline 4 & Blend & 15 & 9.6 \\
\hline 5 & Blend & 20 & 9.7 \\
\hline 6 & Blend & 25 & 9.8 \\
\hline 7 & Blend & 35 & 9.7 \\
\hline 8 & Blend & 40 & 9.7 \\
\hline 9 & Blend & 45 & 9.8 \\
\hline 10 & Blend & 50 & 9.7 \\
\hline 11 & Blend & 75 & 9.7 \\
\hline 12 & PEO & 100 & 9.8 \\
\hline 13 & Li-block & 27.4 & 11.8 \\
\hline 14 & Gr-block & 29.5 & 13.8 \\
\hline 15 & Gr-block & 17.3 & 11.8 \\
\hline
\end{tabular}

a Polymer (g)/[Polymer $(\mathrm{g})+$ Chromosorb $(\mathrm{g})] \times 100$.

Several days after the first measurement on a freshly packed column, the second measurement was carried out to investigate the influence of the thermal treatment on the phase structure of the polymer.

The surface structure of the blend was observed by scanning electron microscopy (SEM). SEM photographs were obtained on a JEOL JSM-25SII operated at $12.5 \mathrm{kV}$. The polymer was cast from a benzene solution onto a silane-treated glass plate. The samples were coated with $300 \AA$ of gold.

\section{RESULTS AND DISCUSSION}

\section{The Influence of Blend Composition on Retention Diagram}

In Figure 1 are shown the RDs of columns No. 1 and 12 prepared by PMMA and PEO, respectively. In a Z-shaped curve, the temperature of the first deviation from linearity corresponds to the transition temperature of the polymer. ${ }^{7}$ As can be seen from Figure 1, the $T_{\mathrm{m}}$ of PEO and the $T_{\mathrm{g}}$ of PMMA were about 62 and $115^{\circ} \mathrm{C}$, respectively. In the RDs of an incompatible polymer blend system such as 


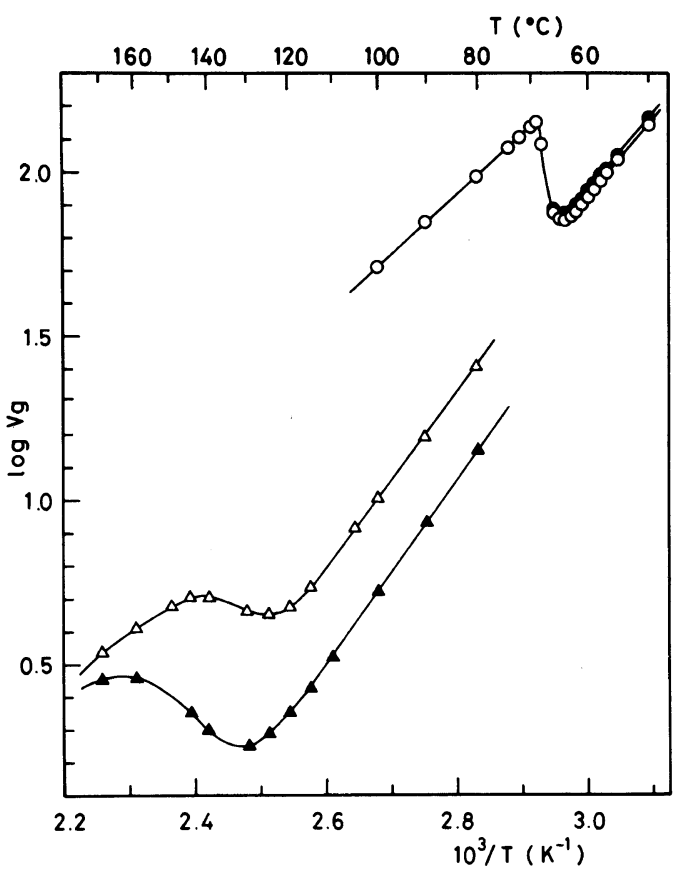

Figure 1. Retention diagrams of PEO and PMMA: (O) column No. 12 (PEO, first measurement); (O) No. 12 (PEO, second); $(\triangle)$ No. 1 (PMMA, first); ( $\Delta)$ No. 1 (PMMA, second).

PEO/PS blends, the two Z-shaped curves appeared in a RD, and the values of $T_{\mathrm{m}}$ and $T_{\mathrm{g}}$ were the same as those of corresponding homopolymers regardless of the composition. ${ }^{13}$ Figures 2 and 3 show the RDs of the blends prepared at various compositions and of PEO and PMMA homopolymers. In the RD of column No. $2(5 \mathrm{wt} \%$ PEO), the Z-shaped curves at 62 and $115^{\circ} \mathrm{C}$ were not observed. Instead, a Z-shaped curve at $97^{\circ} \mathrm{C}$ and a very slight bending of the slope at $58^{\circ} \mathrm{C}$ were observed. The former is mainly attributable to the glass transition of PMMA and the latter to the melt transition of PEO. The depressions of $T_{\mathrm{g}}$ and $T_{\mathrm{m}}$ are consistent with the results of other workers..$^{4,17,20}$ The bending at $58^{\circ} \mathrm{C}$ and a $\mathrm{Z}$ shaped curve at $82^{\circ} \mathrm{C}$ were also observed in a blend of $10 \mathrm{wt} \%$ PEO. The appearance of the new Z-shaped curves means that PEO is compatible with PMMA and acts as a plasticizer to depress the $T_{\mathrm{g}}$ of PMMA. The magnitude of

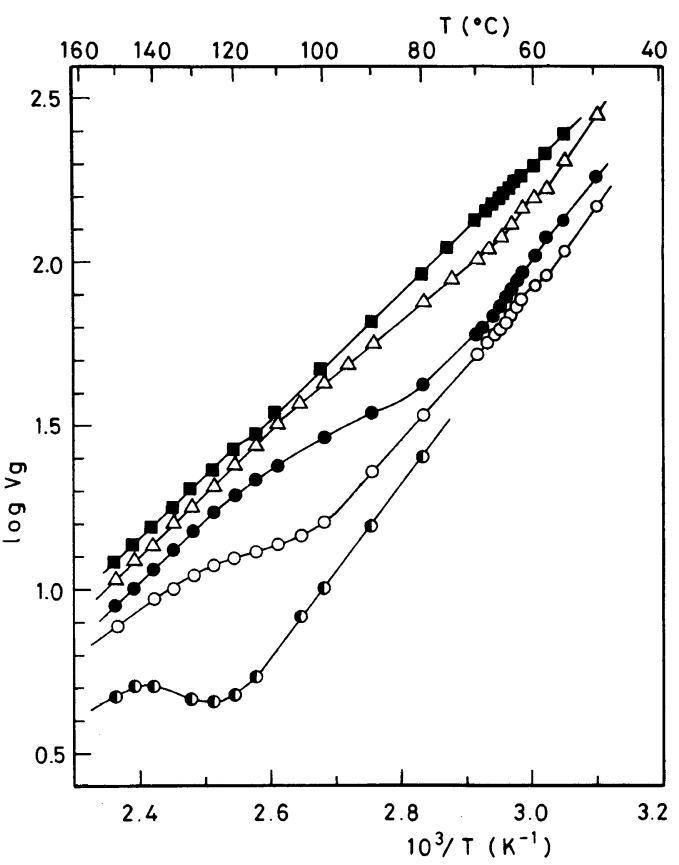

Figure 2. Retention diagrams of PEO/PMMA blends and PMMA (first measurement): $(O)$ column No. 2

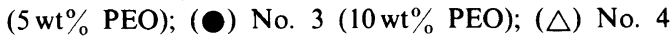
(15wt \% PEO); (ロ) No. 7 (35wt \% PEO); (D) No. 1 (PMMA).

the depression is proportional to the PEO content. In this composition range, it is supposed that the blend is almost homogeneous and the transition behavior is mainly determined by PMMA component.

The RDs of $20,25,40 \mathrm{wt} \%$ PEO were almost identical to the RD of $35 \mathrm{wt}^{\circ} \%$ PEO which was nearly linear. In this composition range, the two components are completely compatible and the blend is a homogeneous polymer system which exhibits no transition phenomenon within the temperature range from 40 to $160^{\circ} \mathrm{C}$.

In the RD of $15 \mathrm{wt} \%$ PEO, only slight bendings of the slope were observed at about 58 and $110^{\circ} \mathrm{C}$, and a Z-shaped curve did not appear. The composition around $15 \mathrm{wt} \%$ PEO corresponds to a transition of the two states mentioned above. This is supported by the results on the thermally treated blend de- 


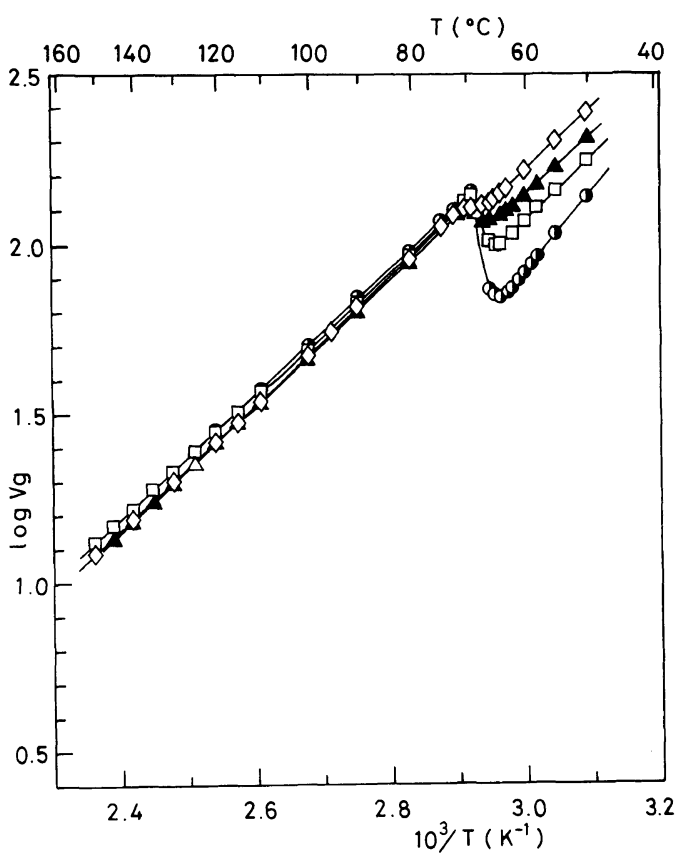

Figure 3. Retention diagrams of PEO/PMMA blends and PEO (first measurement): $(\diamond)$ column No. 9 (45 wt \% PEO); (A) No. 10 (50 wt \% PEO); ( $\square$ ) No. 11 (75 wt \% PEO); () No. 12 (PEO).

scribed below.

As shown in Figure 3, in the RDs of 45, 50 and $75 \mathrm{wt} \%$ PEO, Z-shaped curves were clearly observed at around $62-65^{\circ} \mathrm{C}$ and the depth of each Z-shaped curve increased with PEO content. Bendings of the slopes were hardly observable at around $110^{\circ} \mathrm{C}$. This indicates that, above $c a .45 \mathrm{wt} \%$ PEO, PEO domains exist in the homogeneous polymer matrix appeared in the range of about $20-40 \mathrm{wt} \%$ PEO, and spread out with increase in PEO content.

\section{SEM Photograph of PEO/PMMA Blend}

Figure 4 shows a SEM photograph of a cast film of PEO/PMMA blend prepared at $50 \mathrm{wt} \%$ PEO. The surfaces of the blends containing PEO below $40 \mathrm{wt} \%$ were smooth and homogeneous by SEM observation. In $50 \mathrm{wt} \%$ PEO, as can be seen from Figure 4, PEO domains exist over the homogeneous polymer surface. These SEM observations

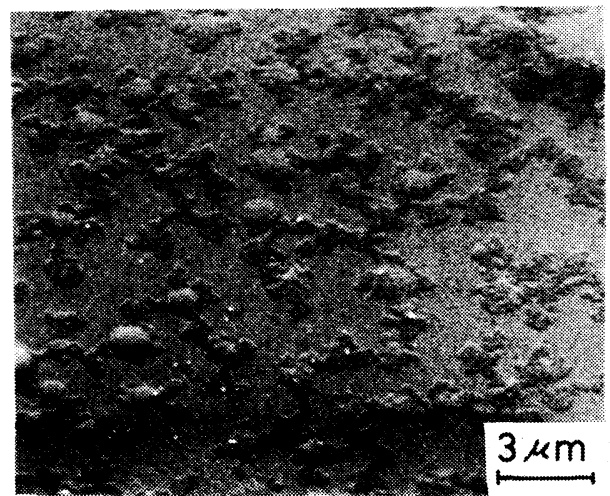

Figure 4. SEM photograph of a PEO/PMMA blend cast from the benzene solution ( $50 \mathrm{wt} \% \mathrm{PEO})$.

are consistent with the IGC results described above.

\section{Effect of Thermal Treatment on the Compati- bility of PEO/PMMA Blend}

In Figure 1 are shown the RDs of the second measurement (RDs-2nd) of the columns No. 1 and 2 together with the RDs of the first measurement (RDs-1st). The RD-2nd reflects the thermally-treated phase structure of the polymer. As previously reported, the retention of a solute is caused by bulk sorption around the Tm of PEO and by surface adsorption below the $T_{\mathrm{g}}$ of PMMA. ${ }^{7,15}$ Since the amount of polymer bulk is constant regardless of thermal treatment, the RD-2nd of PEO was almost the same as the RD-1st. In the RD-2nd of PMMA, a decrease in the value of $\log V_{\mathrm{g}}$ compared with the RD-1st corresponds to a decrease in surface area of the polymer caused by thermal treatment. In short, the result that the RD-2nd is not so different from the RD-1st indicates that the transition behavior of the blend is mainly governed by the PEO component. On the other hand, the result that the value of $\log V_{\mathrm{g}}$ in RD-2nd is smaller than that in the RD-1st indicates that the transition behavior of the blend is mainly governed by PMMA component.

Figures 5 and 6 show the RDs- 1 st and RDs- 


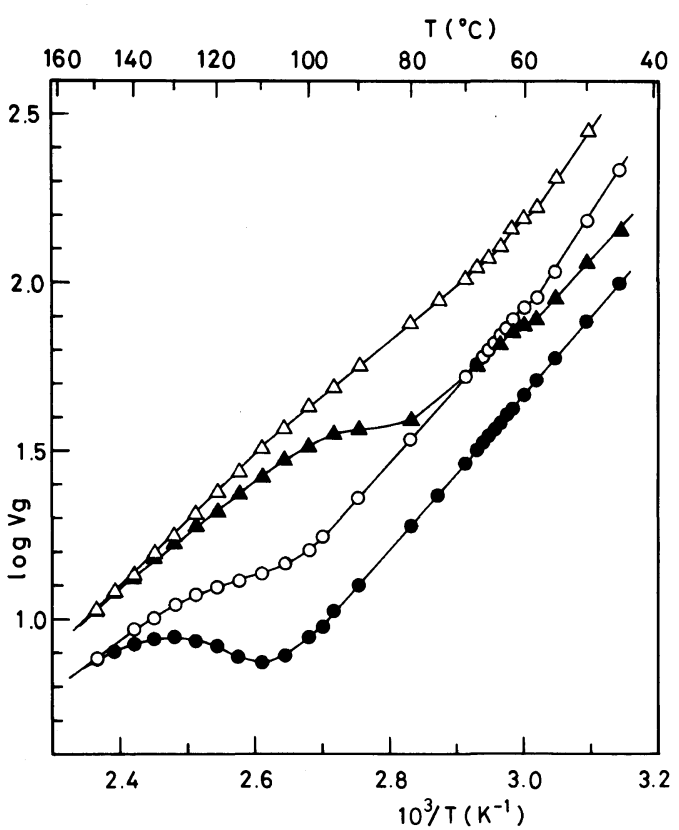

Figure 5. Retention diagrams of PEO/PMMA blends: (O) column No. 2 ( $5 \mathrm{wt} \%$ PEO, first measurement); (O) No. $2(5 \mathrm{wt} \%$ PEO, second $) ;(\triangle)$ No. $4(15 \mathrm{wt} \%$ PEO, first); (A) No. 4 (15 wt \% PEO, second).

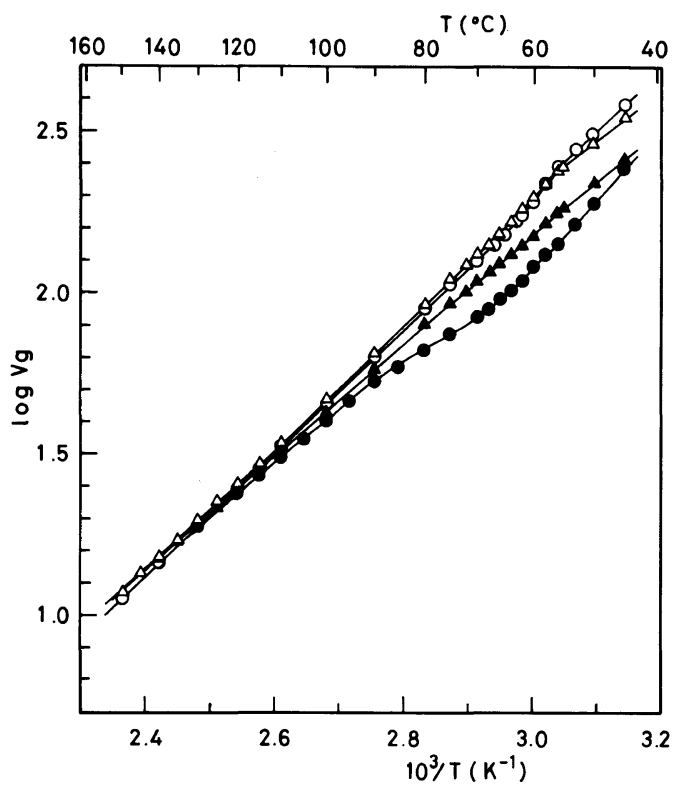

Figure 6. Retention diagrams of PEO/PMMA blends: (O) column No. 5 (20 wt $\%$ PEO, first measurement); (๑) No. 5 (20wt \% PEO, second); $(\triangle)$ No. $6(25 \mathrm{wt} \%$ PEO, first); (A) No. 6 (25 wt \% PEO, second). 2nd of $5,15,20$, and $25 \mathrm{wt} \%$ PEO. In the RD2nd of $5 \mathrm{wt} \% \mathrm{PEO}$, the fundamental pattern of the RD was the same as the RD-1st, while the value of $\log V_{\mathrm{g}}$ decreased. This supports the above-mentioned interpretation; that is, the transition behavior of the blend is mainly determined by PMMA component in $5 \mathrm{wt} \%$ PEO. The same tendency was observed in the RD-1st and RD-2nd of $10 \mathrm{wt} \%$ PEO.

In the RDs of $15 \mathrm{wt} \%$ PEO, the RD was almost linear and a $Z$-shaped curve was not observed in the RD-1st, whereas a Z-shaped curve was clearly observed at around $80^{\circ} \mathrm{C}$ in the RD-2nd. In $15 \mathrm{wt} \% \mathrm{PEO}$, therefore, the property of PMMA does not appear before thermal treatment but appears after it. This was also observed in $20 \mathrm{wt} \%$ PEO. In the RD2nd of $25 \mathrm{wt} \%$ PEO, a Z-shaped curve was not observed and the value of $\log V_{\mathrm{g}}$ very slightly decreased. The RDs-1st and -2 nd of 35 and $40 \mathrm{wt} \%$ PEO were the same as the RD-1st of $25 \mathrm{wt} \%$ PEO. In 25-40 $\mathrm{wt}^{\%} \%$ PEO, two components are completely compatible and the transition behavior of the blend is mainly dominated by PEO component, and the fundamental transition behavior does not change by thermal treatment. The composition of $c a$. $15-25 \mathrm{wt} \%$ PEO corresponds to the critical composition of the two states described above.

Above $45 \mathrm{wt} \%$ PEO, the shape of RD-2nd was completely the same as the respective RD1st. Although the PEO domains existing over the homogeneous polymer matrix may partially melt, the fundamental feature of the blend does not change by thermal treatment.

\section{Compatibility of PEO and PMMA in the Block Copolymers}

Figures 7 and 8 show the RDs-1st, -2 nd of a li-block (27.4 wt \% PEO) and of gr-blocks (17.3 and $29.5 \mathrm{wt} \% \mathrm{PEO}$ ), respectively.

In a previous paper, we reported in detail the transition phenomena of the block copolymers of PEO and PMMA. ${ }^{23}$ In the li-blocks with compositions below $9.4 \mathrm{wt} \% \mathrm{PEO}$, distinct Z-shaped curves were observed at $82^{\circ} \mathrm{C}$, 


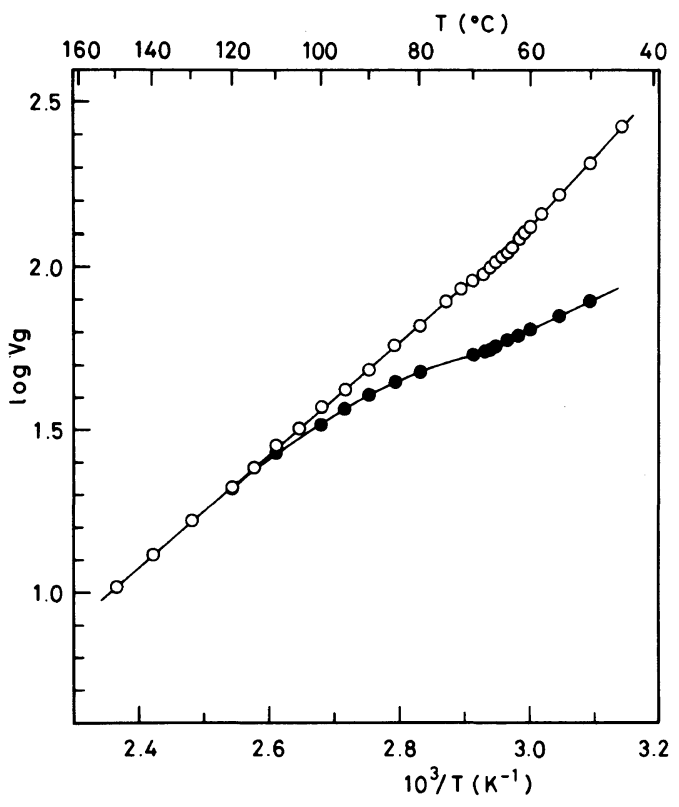

Figure 7. Retention diagrams of a linear triblock copolymer of PEO and PMMA: (O) column No. 13 $(27.4 \mathrm{wt} \%$ PEO, first measurement); (O) No. 13 (27.4 wt \% PEO, second).

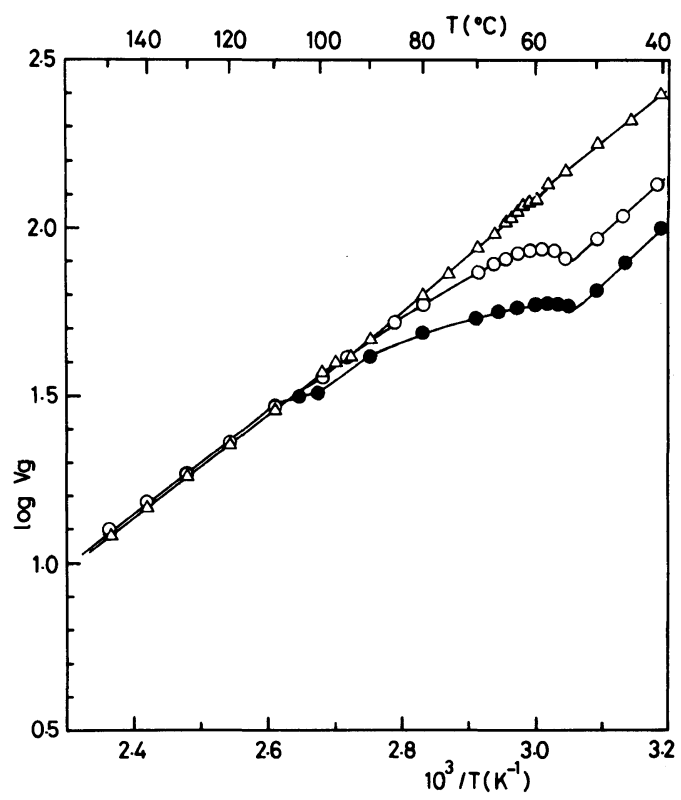

Figure 8. Retention diagrams of PEO-Grafted block copolymers of PEO and PMMA: $\triangle(\triangle)$ column No. 14 (29.5 wt \% PEO, first and second measurements); $(O)$ No. 15 (17.3 wt \% PEO, first); (O) No. 15 (17.3 wt \% PEO, second). which were accounted for by the intramolecular plasticizing effect of the PEO center block. This is consistent with the results on the blends with compositions below $10 \mathrm{wt} \%$ PEO.

In contrast, in the RD-1st of a li-block of $27.4 \mathrm{wt} \%$ PEO depicted in Figure 7, the RD was almost linear and a $\mathrm{Z}$-shaped curve was hardly observable. We presumed that this behavior is ascribed to the low molecular weight of the PMMA block. ${ }^{23}$ On the basis of the results on the blends, however, we conclude that in this composition the two segments are almost compatible and this li-block shows no transition before thermal treatment. In the RD-2nd of this li-block, a weak Z-shaped curve appeared at around $70^{\circ} \mathrm{C}$ and the value of $\log V_{\mathrm{g}}$ decreased. This indicates that the compatibility slightly decreased and the property of PMMA was revealed by thermal treatment.

As expected from the discussion described above, the RD-1st of gr-block of $29.5 \mathrm{wt} \%$ PEO was almost linear as shown in Figure 8. On the other hand, in the RD-1st of a gr-block of lower PEO content ( $17.3 \mathrm{wt} \%$ PEO), a distinct Z-shaped curve due to the melt transition of PEO segment was unexpectedly observed at around $55^{\circ} \mathrm{C}$. Further, a Z-shaped curve due to the glass transition of PMMA segment was slightly observable at around $100^{\circ} \mathrm{C}$. The interpretation of the difference between the two copolymers is as follows.

The gr-block of $29.5 \mathrm{wt} \%$ PEO mainly consisted of PEO-grafted triblock copolymer of PEO and PMMA. Fixation of both chain ends of PEO to the PMMA segments would result in a similar thermal behavior of PEO segment to that in the li-block of $27.4 \mathrm{wt} \%$ PEO. In contrast, the gr-block of $17.3 \mathrm{wt} \%$ PEO mainly consisted of PEO-grafted diblock copolymer of PEO and PMMA in which one of the PEO chain ends was not fixed to a PMMA segment. The increase in the mobility of the PEO segment in this copolymer resulted in similar thermal behavior to that of PEO homopolymer. Since the two Z-shaped curves were 
observed and the value of $\log V_{\mathrm{g}}$ decreased in the RD-2nd, it is reasonable to consider that micro phase separation occurs in this copolymer.

The RD-2nd was completely the same as the RD-1st in the gr-block of $29.5 \mathrm{wt} \%$ PEO, which indicates that the transition behavior of this copolymer is mainly governed by PEO. In this copolymer, the two components are completely compatible and no transition phenomenon was observed in the temperature range from 40 to $150^{\circ} \mathrm{C}$. This feature did not change by thermal treatment. In contrast, the value of $\log V_{\mathrm{g}}$ decreased in the RD-2nd of the li-block of $27.4 \mathrm{wt} \%$ PEO regardless of nearly the same composition as in the gr-block of $29.5 \mathrm{wt} \%$ PEO. It is considered from these results that the ability of PEO to mix with PMMA is greater in the gr-block of $29.5 \mathrm{wt} \%$ PEO than in the li-block of $27.4 \mathrm{wt} \%$ PEO.

\section{CONCLUSIONS}

In PEO/PMMA blends, the transition behavior in the polymer system varies with the blending composition. The following four characteristic morphological states exist: (1) below $c a .15 \mathrm{wt} \%$ PEO; a transition phenomenon is distinctly observed, which is attributed to the glass transition of PMMA. The polymer system is almost homogeneous and the physical property measured by gas chromatography is mainly determined by the PMMA component. The fundamental transition behavior of the blends does not change by thermal treatment. (2) $c a .25-45 \mathrm{wt}^{\circ} \%$ PEO; no transition phenomenon is observed before and after thermal treatment in the temperature range from 50 to $150^{\circ} \mathrm{C}$. The transition behavior of the blends is mainly determined by the PEO component and the two components are completely compatible. These features do not change by thermal treatments. (3) ca. 15-25 wt $\%$ PEO; the fundamental transition behavior of the blends is similar to the state (2) before thermal treatment, and it is similar to the state (1) after thermal treatment. This composition range corresponds to a critical state of the states (1) and (2). (4) above $c a .45 \mathrm{wt} \%$ PEO; PEO domains exist in the homogeneous polymer matrix having the composition comparable to the state (2) and spread out with an increase in PEO content. The fundamental transition behavior of the blends does not change by thermal treatment.

In the li-block, the change in compatibility of the two components with the composition is essentially identical to that in the blend. On the other hand, in the gr-block, compatibility greatly depends on the molecular structure. The ability of PEO to incorporate PMMA is generally greater in the gr-block than in the liblock.

As has been discussed, IGC measurements of multicomponent polymer systems such as polymer blends and block copolymers offer valuable information on transition phenomena, compatibility, thermal treatment and so on. Information on these changes was hardly obtainable by the differential scanning calorimetry (DSC) in our laboratory. Especially, the change in the compatibility by thermal treatment could not be detected by our DSC measurements. Thus, IGC is a simple, sensitive and useful technique and will be widely applicable to studies on other multicomponent polymer systems.

\section{REFERENCES}

1. D. R. Paul and S. Newman, "Polymer Blends," Academic Press, New York, N. Y., 1978.

2. O. Olabisi, L. M. Robeson, and M. T. Shaw, "Polymer-Polymer Miscibility," Academic Press, New York, N. Y., 1979.

3. B. J. Schmitt, Angew. Chem. Int. Ed. Engl., 18, 273 (1979).

4. E. Martuscelli, R. Palumbo, and M. Kryszewski, "Polymer Blends," Plenum Press, New York, N. Y., 1980.

5. S. Akiyama, T. Inoue, and T. Nishi, "Polymer Blend," CMC Press, Tokyo, 1981.

6. H. L. Snyder and P. Meakin, J. Polym. Sci., Polym. 
Symp., No. 73, 217 (1985).

7. J.-M. Braun and J. E. Guillet, Adv. Polym. Sci., 21, 107 (1976).

8. K. Ito, H. Sakakura, and Y. Yamashita, J. Polym. Sci., Polym. Lett. Ed., 15, 755 (1977).

9. K. Ito, H. Sakakura, K. Isogai, and Y. Yamashita, J. Polym. Sci., Polym. Lett. Ed., 16, 21 (1978).

10. M. Galin and M. C. Rupprecht, Macromolecules, 12 , 506 (1979).

11. K. Ito, N. Usami, and Y. Yamashita, Macromolecules, 13, 216 (1980).

12. G. DiPaola-Baranyi, Polym. Prepr., Am. Chem. Soc. Div. Polym. Chem., 21(2), 214 (1980).

13. T. Suzuki, Y. Murakami, T. Inui, and Y. Takegami, Polym. J., 13, 1027 (1981).

14. Y. Murakami, T. Inui, and Y. Takegami, Polymer, 24, 1596 (1983).

15. Y. Murakami, T. Inui, T. Suzuki, and Y. Takegami, Polym. J., 15, 415 (1983).
16. T. Inui, Y. Murakami, T. Suzuki, O. Yamada, and Y. Takegami, Macromolecules, 17, 195 (1984).

17. E. Martuscelli, M. Canetti, L. Vicini, and A. Seves, Polymer, 23, 331 (1982).

18. M. M. Cortazar, M. E. Calahorra, and G. M. Guzmán, Eur. Polym. J., 18, 165 (1982).

19. J. M. Elorza, M. J. Fdz-Berridi, J. J. Iruin, and G. M. Guzmán, Polym. Eng. Sci., 24, 287 (1984).

20. M. E. Calahorra, M. M. Cortazar, and G. M. Guzmán, J. Polym. Sci., Polym. Lett. Ed., 23, 257 (1985).

21. T. Suzuki, Y. Murakami, Y. Tsuji, and Y. Takegami, J. Polym. Sci., Polym. Lett. Ed., 14, 675 (1976).

22. T. Suzuki, Y. Murakami, and Y. Takegami, Polym. J., 12, 183 (1980)

23. T. Suzuki, O. Yamada, Y. Murakami, Y. Takegami, and Y. Watanabe, Macromolecules, 15, 223 (1982).

24. T. Inui, Y. Murakami, T. Suzuki, and Y. Takegami, Polym. J., 14, 261 (1982). 